\title{
28 Research Square \\ SapC-DOPS: A promising new way to target and kill cancer
}

Kombo F. N’Guessan, Priyankaben H. Patel, Xiaoyang Qi

\section{Video Byte}

Keywords: SapC-DOPS, cancer, treatment, phosphatidylserine, cell membrane, apoptosis, tumor, nanovesicle

Posted Date: May 5th, 2020

DOl: https://doi.org/10.21203/rs.3.rs-27208/v1

License: (c) (i) This work is licensed under a Creative Commons Attribution 4.0 International License. Read Full License 


\section{Abstract}

Phosphatidylserine (PS) is a fatty substance normally located on the inner membrane of healthy cells, but cancer cells tend to express high levels of PS on their surface. That tiny difference has paved the way for a new cancer-targeting agent called SapC-DOPS. SapC-DOPS is a nanovesicle that effectively targets and kills several types of cancer, including pancreatic, lung, brain, and pediatric cancers, while leaving surrounding cells unharmed. The nanovesicle achieves this by selectively inducing apoptotic cell death in malignant and metastatic cancer cells rich in surface PS. One phase I clinical trial showed that SapCDOPS was safe and yielded favorable outcomes in patients with solid tumors, but more pre-clinical studies are needed to better understand the properties of SapC-DOPS, including how SapC-DOPS can eliminate cancer cells that express high levels of surface PS but evade apoptotic cell death and how effective SapC-DOPS is in treating advanced cancers. Such studies could help streamline SapC-DOPS and maximize its ability to fight cancer. 